Choi Yj. ANALYSIS OF POSTOPERATIVE ULTRASONOGRAPHY SURVEILLANCE AFTER HEMITHYROIDECTOMY IN PATIENTS WITH PAPILLARY THYROID MICROCARCINOMA: A MULTICENTER STUDY. Endocr Pract Off J Am Coll Endocrinol Am Assoc Clin Endocrinol.
2017;23(7):794-802. doi:10.4158/EP161723.OR

9. Kim DW. Long-term follow-up ultrasonography after lobectomy in papillary thyroid microcarcinoma patients: A single-center study. Endocr Res. 2016:41(3):213-217.

doi:10.3109/07435800.2015.1137583

\title{
TÌM HIỂU VAI TRÒ CỦA CA 125, HE4 VÀ ROMA TEST TRONG DƯ ĐOÁN UNG THƯ BUỒNG TRỨNG TẠI BÊ̂NH VIỆN PHỤ SẢN HÀ NộI
}

\section{Phan Đức Long ${ }^{1}$, Lê Thị Anh Đào ${ }^{2}$, Trương Quang Vinh ${ }^{3}$}

\section{TÓM TẮT}

Chẩn đoán ung thư buồng trứng sớm thường rất khó khăn do các dấu hiệu lậm sàng mờ nhat, biên pháp chẩn đoán hình ảnh phu thuộc rất nhiều vào kinh nghiệm và kỹ năng của người đọc. Các xét nghiêm $\mathrm{CA} 125$ và $\mathrm{HE} 4$ và ROMA test đã được chứng minh có khả năng dự đoán nguy cơ ung thư của khối u buồng trứng. Nghiên cứu nhằm mục tiêu: Xác định giá trị dự đoán của CA125, HE4 và ROMA test trong ung thư buồng trứng tại quần thể bệnh nhân u buồng trứng được phẫu thuật tại bệnh viện Phụ Sản Hà Nối năm 2018-2019. Nghiên cứu mô tả cắt ngang, tiến cứu từ 8/2018 đến tháng 6/2019. Các bệnh nhân có u buồng trứng xét nghiệm CA 125 HE4 và ROMA test trước mổ sau đó được phẫu thuật tại bệnh viện Phu Sản Hà Nội. Dưa theo kết quả giải phấu bệnh lý sau mổ để đánh giá độ nhậy, độ đặc hiệu của 3 xét nghiệm này. Kết quả: Trong 209 bệnh nhân u buồng trứng, có 33 bệnh nhân ung thư buồng trứng. Độ nhậy và độ đặc hiệu của CA125 trong ung thư biểu mô buồng trứng (UTBMBT) là $88 \%, 70 \%$. Độ nhạy và độ đặc hiệu của HE4 trong UTBMBT là $64 \%$ và $96.6 \%$. Độ nhạy và độ đặc hiệu của ROMA test trong UTBMBT là $92 \%$, độ đẳc hiệu ROMA $=55.32 \%$. Kết luân: $C A$ 125 và HE4 riêng lẻ đều có giá trị dự đoán UTBMBT, nên phối hợp CA 125 và HE4 trong dự đoán UTBMBT.

Tư khóa: CA 125, HE4, ROMA test, ung thư biểu mô buồng trứng

\section{SUMMARY CA125, HE4 AND ROMA TESTS IN \\ ${ }^{1}$ Bệnh viện Đa Khoa Nông Nghiệp \\ ${ }^{2}$ Dại học Y Hà Nọi \\ ${ }^{3}$ Trường Đại học Y Dược, ĐHQG Hà Nọi \\ Chịu trách nhiệm chính: Lê Thị Anh Đào \\ Email: leanhdao1610@gmail.com \\ Ngày nhân bài: 22.10.2021 \\ Ngày phản biên khoa họ: 17.12.2021 \\ Ngày duyệt bài: 27.12.2021}

DETERMINE THE PREDICTED VALUE OF DIAGNOSE OVARIAN CANCER AT HANOI OBSTETRICS AND GYNECOLOGY HOSPITAL

Diagnosis of ovarian cancer is often late and difficult, due to the lack of specific signs. Ultrasounds or IRM images can not diagnose ovarian cancer as well. CA 125 and HE 4 tests and ROMA tests have been shown to predict ovarian cancer risk. The study aims to: Determine the predicted value of CA125, HE4 and ROMA tests in diagnose ovarian cancer in the population of ovarian tumor patients undergoing surgery at Hanoi Obstetrics and Gynecology hospital in 2018-2019. This is a cross sectional study has implemented from August 2018 to June 2019. Patients with ovarian tumors have been tested CA 125, HE4 and ROMA test before surgery. Based on the pathology's results after surgery to assess the sensitivity and specificity of these 3 tests. Results: Of the 209 patients with ovarian cancer, 33 had ovarian cancer. The sensitivity and specificity of CA125 in ovarian carcinoma are $88 \%, 70 \%$. The sensitivity and specificity of HE4 in UTBMBT are $64 \%$ and $96.6 \%$. The sensitivity and specificity of ROMA test in UTBMBT are $92 \%$, specificity ROMA $=55.32 \%$. Conclusions: CA 125 and HE4 have predictive values in diagnosing ovarian cancer, the combination between CA 125 and HE4 is better than single test.

\section{I. ĐĂT VẤN ĐỀ}

Ung thư buông trứng (UTBT) là loại ung thư ác tính nhất trong các ung thư phụ khoa, có tỷ lệ đứng thứ 3 sau ung thư cổ tử cung và ung thư vú ở phụ nữ, chiếm khoảng $5 \%$ trong các bệnh ung thư ở nữ giới [1]. Ở Việt Nam, tỷ lệ này là khoảng 3 đến 4.5/100.000 phụ nữ mỗi năm [2].

Tỷ lệ tử vong của UTBT cao và tỷ lệ sống sót tương đối trên 5 năm chưa đến $40 \%$ do bệnh thường chỉ được phát hiện ở giai đoạn muộn, chỉ khoảng 15\% số trường hợp được phát hiện sớm mà thôi [3]. Để chẩn đoán sớm UTBT thường phải kết hợp lâm sàng với các phương pháp chẩn đoán hình ảnh và xét nghiệm chất chỉ điểm $u$. Tuy nhiên, các triệu chứng lâm sàng trong giai đoan sớm của bệnh thường nghèo nàn. Các hình ảnh siêu âm để phát hiện ung thư buồng trứng cũng tương đối phong phú và đòi hỏi kinh nghiệm của người làm siêu âm. Do đó, việc dự đoán ung thư buồng trứng trước mố dựa rất nhiều vào xét nghiệm chất chỉ điểm u. Hiện nay, chất chỉ điểm u thường được dùng để dự đoán ung thư buồng trứng trên thế giới là CA125 (cancer antigen 125 ) và HE4 (human epididymal 
protein 4) [4],[5]. ROMA test là kết quả kết hợp 2 nồng độ xét nghiệm chỉ điểm u là $C A 125$ và HE4. Nghiên cứu này được tiến hành với mục tiêu: Xác định giá tri dư đoán của CA125, HE4 và ROMA test trong UTBT tại quần thể bênh nhân u buồng trứng được phẫu thuật tại bệnh viện Phụ Sản Hà Nội năm 2018-2019.

\section{II. ĐỐI TƯƠ'NG VÀ PHƯƠNG PHÁP NGHIÊN CỨU \\ 2.1. ĐỐI TƯƠNG NGHIÊN CỨU}

2.1.1. Tiêu chuẩn lựa chọn bệnh nhân. Bệnh nhân có khối u buồng trứng thực thể (lành tính và ác tính) được chẩn đoán và phẫu thuật tai khoa Phụ A5 bệnh viện Phụ Sản Hà Nội, được làm các xét nghiệm HE4, CA-125 trước mổ. Sử dụng kết quả giải phẫu bệnh sau mổ để xác định khối u buồng trứng lành tính hay ác tính và có nguồn gốc loại tế bào nào.

\subsubsection{Tiêu chuẩn loại trừ}

- Bệnh nhân đã được chẩn đoán và điều trị, phẫu thuật UTBT trước đó tại cơ sở khác.

- Bệnh nhân đang mang thai đồng thời có u buồng trứng

- Bệnh nhân có tiên sử mắc ung thư đại tràng, phổi, niêm mạc tử cung...

\subsection{Phương pháp nghiên cứu}

\subsubsection{Thiêt kếnghiên cứu}

Đây là một nghiên cứu mô tả cắt ngang, tiến cứu, tiến hành tại khoa Phụ $A 5$ bệnh viện Phụ Sản Hà Nội trong thời gian 8/2018 đến tháng 6/2019. Lây mẫu thuận tiện trong khoảng thời gian.

Các bệnh nhân khi vào viện được xét nghiệm
CA 125, HE4 và ROMA test trước mổ, bệnh viện Phụ Sản Hà Nội sử dụng kit xét nghiệm Cobas e601 do hãng Hitachi sản xuất.

Sau mổ sẽ dựa vào kết quả giải phẫu bệnh lý mà chia thành lành tính hay ác tính, đồng thời theo nguồn gốc của tế bào mà chia 2 quân thể: nhóm chung (có nguồn gốc biểu mô, mầm, sợi sinh dục) và nhóm biểu mô (có nguồn gốc tế bào biểu mô).

Từ đó tính độ nhậy, độ đặc hiệu của các xét nghiệm CA 125, HE4 và ROMA để dự đoán nguy cơ ung thu'.

2.2.2. Các biến sốnghiên cứu và tiêu chuẩn

- Giải phẫu bệnh lý lành tính hay ác tính sau mổ, phân loại nguồn gốc khối u từ tế bào biểu mô của buồng trứng hay tế bào mầm hay sợi sinh duc.....

- Giá trị CA125, HE4 và ROMA test của từng bệnh nhân trước mổ

*CA 125 Người bình thường < 35 UI/I là bình thường [6], [7].

*HE4: Bình thường, ở phụ nữ HE4 có giá trị $<70 \mathrm{pmol} / \mathrm{l}$ đối với phụ nữ chưa mãn kinh và < 140pmol/l đối với phụ nữ mãn kinh [8].

*ROMA: Cách tính chỉ số ROMA (Rist of ovarian malignancy algorithm: chỉ số nguy cơ ác tính của u buồng trứng) [9].

Phụ nữ chưa mãn kinh: nếu ROMA $\geq 7.4 \%$, nguy cơ ác tính cao

Phụ nữ sau mãn kinh: nếu ROMA $\geq 25.3 \%$, nguy cơ ác tính cao.

- Độ nhạy, độ đặc hiệu của HE4, CA-125, test ROMA.

\section{KẾT QUẢ NGHIÊN CỨU}

Trong tổng số 209 bệnh nhân, có 33 bệnh nhân ung thư buồng trứng, chiếm tỷ lệ 15.8\%.

\section{1. Độ nhay và độ đăc hiệu của các chất chỉ điểm u}

Bảng 3.1. Độ nhậ và độ đặc hiệu của CA125

\begin{tabular}{|c|c|c|c|c|c|}
\hline \multicolumn{2}{|c|}{} & \multicolumn{2}{c|}{ Nhóm chung } & \multicolumn{2}{c|}{ Nhóm biếu mô } \\
\cline { 3 - 6 } & Ung thư & Lành tính & Ung thư' & Lành tính \\
\hline \multirow{2}{*}{ CA 125 125} & $>35 \mathrm{U} / \mathrm{ml}$ & 26 & 37 & 22 & 28 \\
\cline { 2 - 6 } & $\leq 35 \mathrm{U} / \mathrm{ml}$ & 7 & 139 & 3 & 66 \\
\hline \multicolumn{2}{|c|}{ Tống } & $\mathbf{3 3}$ & $\mathbf{1 7 6}$ & $\mathbf{2 5}$ & $\mathbf{9 4}$ \\
\hline
\end{tabular}

Trong nhóm chung: Độ nhậy CA125 = 78.79\%, độ đặc hiệu CA125 = 78.98\%

Trong nhóm biểu mô (khi đã loại bỏ các loại UBT không có nguồn gốc từ biểu mô): Độ nhậy CA125: 88\%, đô đăc hiêu CA125: 70\%

Bảng 3.2. Độ nhạy và độ đặc hiệu của HE4

\begin{tabular}{|c|c|c|c|c|c|}
\hline \multirow{2}{*}{ Tình trạng KN } & \multicolumn{2}{c|}{ Nhóm chung } & \multicolumn{2}{c|}{ Nhóm biếu mồ } \\
\cline { 2 - 6 } & Ung thư' & Lành tính & Ung thư & Lành tính \\
\hline \multirow{2}{*}{$\begin{array}{c}\text { BN đáng } \\
\text { có kinh }\end{array}$} & $\mathrm{HE4}>70 \mathrm{pmol} / \mathrm{l}$ & 12 & 4 & 10 & 3 \\
\cline { 2 - 6 } & $\mathrm{HE4} \leq 70 \mathrm{pmol} / \mathrm{l}$ & 7 & 154 & 4 & 74 \\
\hline \multirow{2}{*}{ BN mãn kinh } & $\mathrm{HE} 4>140 \mathrm{pmol} / \mathrm{l}$ & 7 & 0 & 6 & 0 \\
\cline { 2 - 6 } & $\mathrm{HE} 4 \leq 140 \mathrm{pmol} / \mathrm{l}$ & 7 & 18 & 5 & 17 \\
\hline \multicolumn{2}{|c|}{ Tống } & $\mathbf{3 3}$ & $\mathbf{1 7 6}$ & $\mathbf{2 5}$ & $\mathbf{9 4}$ \\
\hline
\end{tabular}

Trong nhóm chung: Độ nhậy HE4 = 57.57\%, độ đặc hiệu HE4 = 97.72\% 
Dưới nhóm đang có kinh: Độ nhậy HE4 = 63.15\%, độ đặc hiệu HE4 = 97.46\%

Dưới nhóm mãn kinh: Độ nhậy HE4 = 50\%, độ đặc hiệu HE4 = 100\%

Trong nhóm biểu mô: Độ nhậy HE4 $=64 \%$, độ đặc hiệu HE4 $=96.6 \%$

Dưới nhóm đang có kinh: Độ nhậy HE4 = 71.4\%, độ đặc hiệu HE4 = 96.1\%

Dưới nhóm mãn kinh: Độ nhậy HE4 = 54.5\%, độ đặc hiệu HE4 = 100\%

Bảng 3.3. Độ nhạy và độ đặc hiệu của ROMA test

\begin{tabular}{|c|c|c|c|c|c|}
\hline \multirow{2}{*}{\multicolumn{2}{|c|}{ (2) }} & \multicolumn{2}{|c|}{ Nhóm chung } & \multicolumn{2}{|c|}{ Nhóm biếu mô } \\
\hline & & Ung thu & Lành tính & Ung thu' & Lành tính \\
\hline \multirow[b]{2}{*}{ BN đang có kinh } & $\mathrm{R} \geq 7,4 \%$ & 15 & 55 & 13 & 42 \\
\hline & $R<7,4 \%$ & 4 & 103 & 1 & 35 \\
\hline \multirow{2}{*}{ BN mãn kinh } & $R \geq 25.3 \%$ & 12 & 0 & 10 & 0 \\
\hline & $\mathrm{R}<25.3 \%$ & 2 & 18 & 1 & 17 \\
\hline \multicolumn{2}{|c|}{ Tống } & 33 & 176 & 25 & 94 \\
\hline
\end{tabular}

Trong nhóm chung: Độ nhậy của ROMA = $81.81 \%$, độ đặc hiệu ROMA $=68.75 \%$

Dưới nhóm đang có kinh: Độ nhậy ROMA = $78.94 \%$, độ đặc hiệu ROMA $=65.18 \%$

Dưới nhóm mãn kinh: Độ nhậy ROMA = $85.71 \%$, độ đặc hiệu ROMA $=100 \%$

Trong nhóm u biểu mô: Độ nhậy ROMA = $92 \%$, độ đặc hiệu ROMA = 55.32\%

Dưới nhóm đang có kinh: Độ nhậy ROMA = $92.8 \%$, độ đặc hiệu ROMA = 45.45\%

Dưới nhóm mãn kinh: Độ nhậy ROMA = $90.9 \%$, độ đặc hiệu ROMA = 100\%

\section{BÀN LUÂN}

Nghiên cứu này được thực hiện nhằm đánh giá khả năng dự đoán ung thư của CA125, HE4 và ROMA test đối với các khối u buồng trứng, đặc biệt là u có nguồn gốc tế bào biểu mô. Dựa trên tiểu chuẩn vàng là kết quả giải phẫu bệnh lý sau phẫu thuật, nghiên cứu so sánh với giá trị thực của $\mathrm{CA} 125$, HE4 và ROMA test với ngưỡng tiêu chuẩn (CA125 là $35 \mathrm{UI} / \mathrm{ml}$, của HE4 và ROMA test tương ứng là $70 \mathrm{pmol} / \mathrm{I}$ và $7.4 \%$ ở phu nữ đang có kinh; $140 \mathrm{pmol} / \mathrm{l}$ và $25.3 \%$ ở phụ nũ mãn kinh) để tính độ nhậy độ đặc hiệu của từng chất đánh dấu khối u.

Trong nghiên cứu này, CA125 cho độ nhạy và độ đặc hiệu trong nhóm chung và nhóm biểu mô nói riểng lần lượt là $78.79 \% ; 78.98 \%$ và $88 \% ; 70 \%$. Có thể thấy rằng độ nhạy của CA125 trong nhóm UTBMBT cao hơn so với quần thể chung vì trong các quần thể ung thư buồng trứng nói chung: UTBMBT là 25 trường hợp $(76 \%)$, ung thư tế bào mầm 5 trường hợp $(15 \%)$ và ung thư tế bào hạt 3 trường hợp $(9 \%)$.

Ngược lại, độ đặc hiệu của CA125 trong nhóm UTBMBT thì lại thấp hớn trong UTBT chung bởi vì ngoài tăng cao ở UTBMBT, CA125 còn tăng cao trong huyết thanh, sữa, dịch ối ở phụ nữ có thai, nhưng không thường xuyên. Ngoài ra, CA 125 cũng tăng cao trong một số u ác tính (của phổi, vú, tuyến tự, gan, các ung thư sinh dục...) và một số bệnh lành tính (viêm nội mạc tử cung, viêm vùng chậu, hội chứng quá kích buồng trứng và $x \sigma ̛$ gan), CA125 còn tăng trong những trường hợp lạc nội mạc tử cung và còn thay đổi (tăng cao nhất ở những ngày hành kinh) trong chu kỳ kinh nguyệt của những bệnh nhân này. Chính vì vậy, độ đặc hiệu của CA125 trong nhóm ung thư biểu mô cũ̃ng không cao. Kết quả của nghiên cứu này cũng phù hợp với kết quả của các nghiên cứu khác trên thể giới: nghiên cứu của Pengjun Zhang và cộng sự (2015), CA125 có độ nhạy và độ đặc hiệu lần lượt là $86,7 \%$ và $72,3 \%$; nghiên cứu của Ortiz-Munoz và cộng sự (2014) có độ nhạy và độ đặc hiệu của CA125 là $86.2 \%$ và $78.9 \%$.

Trái ngược với CA125, HE4 cho độ đặc hiệu cao hơn so với độ nhạy. Trong nghiên cứu của chúng tôi, HE4 cho độ nhạy, độ đặc hiệu lần lượt là $57.57 \%$ và $97.72 \%$ ở nhóm UTBT nói chung và $64 \% ; 97.46 \%$ ở nhóm UTBMBT nói riêng. Trong nghiên cứu này, HE4 đều cho độ đặc hiệu rất tốt (tất cả đều trên $95 \%$ ở các nhóm). Jacob F và cộng sự cũng nhận định ưu điểm chính của HE4 là ở độ đặc hiệu cao và khả năng phát hiên UTBT ở giai đoạn đầu. Vì nồng độ HE4 hiện diện rất thấp trong biểu mô của các mô hô hấp và sinh sản bình thường, do đó, không giống như CA125 có thể tăng cao trong một số bệnh lành tính và ác tính khác, HE4 cho độ dương tính giả rất thấp. Tuy nhiên độ nhạy của HE4 trong nghiên cứu này là 57 ở nhóm chung và 64 ở nhóm ung thư biểu mô, thấp hơn so với kết quả của Van Gorp (2011) là $74.5 \%$ và Jacob $F$ (2011) là $78.9 \%$, nhưng tương tự với kết quả của Chan KK (2013), HE4 cho độ nhạy 56.9\%. Có sự khác biệt về độ nhạy của HE4 trong các nghiên cứu có thể do mức HE4 bình thường là khác nhau ở các tộc người châu Á và da trắng, vì thế cần có những nghiên cứu với cỡ mẫu đủ lớn để tìm hiểu về nồng độ bình thường của HE4 trong quần thể người Việt Nam. 
Độ nhạy và độ đặc hiệu của ROMA trong UTBT chung là $81.81 \%$ và $68.75 \%$; trong nhóm đang có kinh là $78.94 \%$ và $65.18 \%$; và nhóm mãn kinh thì độ nhậy, độ đặc hiệu này cao hơn rất nhiêu lần lượt là $85.71 \%$ và $100 \%$, riêng trong nhóm UTBMBT, ROMA có độ nhạy cao nhất $92 \%$. Kết qủa của chúng tôi tương tự kết quả tác giả trong nước: nghiên cứu của Võ Thanh Nhân (2010) độ nhay của ROMA là 88,2\% và độ đặc hiệu là $64,3 \%$, nhưng khác với tác giả nước ngoài: Anton và cộng sự (2012) nghiên cứu trên 128 bệnh nhân cho thây độ nhay của ROMA là $74,1 \%$ và độ đặc hiệu là $75,8 \%$, nghiên cứu của Su Wei và cộng sự trên 158 trường hợp có độ nhạy 93,75\% và độ đặc hiệu 92,55\%. Karlsen và cộng sự khuyến nghi sử dụng ROMA đặc biệt là ở phụ nữ mãn kinh để dự đoán UTBT chính xác hơn.

Từ những kết quả của nghiên cứu này, chúng tôi nhận thấy: các xét nghiệm CA125, HE4 và ROMA test đều có giá trị tốt để chẩn đoán UTBMBT và cả UTBT nói chung. Nhưng HE4 riêng lẻ hoặc kết hợp HE4 và CA125 có giá trị tốt hơn so với CA125 đởn thuần.

\section{KẾT LUÂN}

Các chất chỉ điểm khối u CA125, HE4 và ROMA test đều có giá trị tốt trong chẩn đoán UTBT nói chung và UTBMBT nói riêng. ROMA cho độ nhạy cao nhất là $92 \%$ và HE4 cho độ đặc hiệu cao nhất $96.6 \%$ trong UTBMBT. Nên kết hợp CA125 và HE4 trong dự đoán UTBMBT.

\section{TÀI LIÊU THAM KHẢO}

1. Pearce C.L., Stram D.O., Ness R.B. et al. (2015). Population Distribution of Lifetime Risk of Ovarian Cancer in the United States. Cancer Epidemiol Biomarkers \&amp;amp; Prev, 24(4), $671 \mathrm{LP}-676$.

2. Ferlay J., Soerjomataram I., Dikshit R. et al. (2015). Cancer incidence and mortality worldwide: sources, methods and major patterns in GLOBOCAN 2012. Int J cancer, 136(5), E359-86.

3. Li K., Hüsing A., Fortner R.T. et al. (2015). An epidemiologic risk prediction model for ovarian cancer in Europe: The EPIC study. $\mathrm{Br}$ J Cancer, 112(7), 1257-1265

4. LaVigne K., Dao F., Abu-Rustum N. et al. (2017), HE4 is a biomarker for newly diagnosed and recurrent high - grade serous ovarian cancer with normal CA 125 values.

5. Moore R.G., McMeekin D.S., Brown A.K. et al. (2009). A novel multiple marker bioassay utilizing HE4 and CA125 for the prediction of ovarian cancer in patients with a pelvic mass. Gynecol Oncol, 112(1), 40-6.

6. Aslam N., Banerjee S., Carr J. V et al. (2000). Prospective evaluation of logistic regression models for the diagnosis of ovarian cancer. Obstet Gynecol, 96(1), 75-80.

7. Piek J.M.J., van Diest P.J., Verheijen R.H.M. (2008). Ovarian carcinogenesis: an alternative hypothesis. Adv Exp Med Biol, 622, 79-87.

8. Dikmen Z.G., Colak A., Dogan P. et al. (2015). Diagnostic performances of CA125, HE4, and ROMA index in ovarian cancer. Eur J Gynaecol Oncol, 36(4), 457-462.

9. Huy N.V.Q., Van Khoa V., Tam L.M. et al. (2018). Standard and optimal cut-off values of serum ca-125, HE4 and ROMA in preoperative prediction of ovarian cancer in Vietnam. Gynecol Oncol reports, 25, 110-114.

\section{NGUYÊN NHÂN, XỬ TRÍ VÀ KẾT QUẢ SỚM ĐIỀU TRI THỦNG THỰC QUẢN}

\section{TÓM TẮT}

Đặt vấn đề: Thủng thực quản là một bệnh lý hiếm gặp nhưng tỉ lệ biến chứng và tử vong cao. Tổn thương có nhiều vị trí và mức độ lan rộng khác nhau khiến việc chẩn đoán ban đâuu thường gặp nhiều khó khăn. Lựa chọn phương pháp điều trị tốt nhất cho bệnh nhân khác nhau tùy vào đặc điểm tổn thương.

*Đại học Quốc Gia TP. Hồ Chí Minh

** Đai hoc Y Dước TP. Hồ Chí Minh

Chịu trách nhiệm chính: Lý Minh Tùng

Email: Imtung@medvnu.edu.vn

Ngày nhận bài: 18.10.2021

Ngày phản biên khoa hoc: 20.12.2021

Ngày duyệt bài: 28.12.2021

\section{Dương Bá Lập**, Lý Minh Tùng*, Trần Văn Minh Tuấn*, Trần Hữu Duy*}

Nghiên cứu này nhằm mô tả nguyên nhân và đánh giá hiêu quả của các phương pháp điều tri thủng thực quản từ 06.2014 đến 06.2019 tại bệnh viện Bình Dân. Muc tiêu: Mô tả nguyên nhân, đắc điểm lâm sàng của tổn thương, hình ảnh học và đánh giá kết quả điều trị các trường hợp thủng thực quản. Đối tượng và phướng pháp nghiên cứu: Mô tả hàng loạt ca được chẩn đoán và điêu trị thủng thực quản tại bệnh viện Bình Dân trong khoảng thời gian 5 năm từ 06.2014 đến 06.2019. Kết quả: Có 36 bệnh nhân, gồm 17 ca thủng thực quản ở cổ (47\%), 15 ca ở ngực (42\%) và 4 ca ở bụng $(11 \%)$. Nguyên nhân chính gầy thủng thực quản là do dị vật $(41,7 \%)$. CT giúp phát hiên tổn thương $94 \%$. Có 8 ca điêuu trị bảo tồn, tỉ lệ thành công là $75 \%$. Khâu thì đâu có tỉ lệ thành công là $87,5 \%$. Tỉ lệ tử vong chung là $8,3 \%$. Kết luận: Thủng 